\title{
Does Surgery Have a Relevant Role in the Primary Treatment of Locoregionally Advanced Oropharyngeal Carcinomas?
}

\author{
Joana Guimarães, Sara Cruz, Eduardo Breda, Eurico Monteiro \\ Department of Otorhinolaryngology and Head and Neck Surgery, Portuguese Institute of Oncology—Francisco Gentil, \\ Oporto, Portugal \\ Email: joanarguimaraes@gmail.com
}

Received August 26, 2013; revised September 25, 2013; accepted October 5, 2013

Copyright (C) 2013 Joana Guimarães et al. This is an open access article distributed under the Creative Commons Attribution License, which permits unrestricted use, distribution, and reproduction in any medium, provided the original work is properly cited.

\begin{abstract}
Background: Treatment concepts for oropharyngeal squamous cell carcinomas are controversial. This review compares the results obtained by distinct treatment options in locoregionally oropharyngeal advanced carcinomas: primary surgical resection followed by concurrent chemoradiotherapy and concurrent chemoradiotherapy alone. Methods: 57 patients with stage III and IV oropharyngeal squamous cell carcinoma were selected. 17 patients were treated with primary surgical resection followed by concurrent chemoradiotherapy and 40 patients were treated only with concurrent chemoradiotherapy. Statistical analysis was performed regarding survival rates according to tumor location, stage, treatment regimen and recurrence. Results: Two-year loco-regional control rates were $94 \%$ after surgery plus chemoradiotherapy and $55 \%$ after chemoradiotherapy $(\mathrm{p}=0.016)$. Progression free survival rates were $88 \%$ and $27 \%$, respectively $(\mathrm{p}<0.001)$. Overall survival rates were $88 \%$ and $45 \%$, respectively $(\mathrm{p}=0.002)$. Conclusions: In this study, primary surgical resection followed by concurrent chemoradiotherapy showed better clinical outcomes with a lower risk of death associated with tumor and tumor progression.
\end{abstract}

Keywords: Oropharyngeal Carcinoma; Treatment; Concurrent Chemoradiotherapy; Primary Surgical Resection; Survival Rates

\section{Introduction}

Seventy percent of oropharyngeal tumors are squamous carcinoma and they represent the third most frequent head and neck cancers, following laryngeal and oral cavity cancers. It accounts for 10 - 15 percent of all head and neck tumors and has an annual incidence in the UK population of approximately ten per million per year [1]. A significant increase in the incidence has been observed in the United States and Western Europe in people $<45$ years old in the last few years [2]. During the period in analysis, around 85 patients per year, appear in our institution, a reference center for oncologic patients for a population of approximately 3,300,000 habitants [3]. Although tobacco and alcohol abuse are the major factors related to the development of these malignancies, substancial molecular and epidemiologic evidence has suggested that human papillomavirus (HPV) is an emerging etiologic factor [4].

Squamous cell carcinoma of the oropharynx is an ag- gressive malignancy with a high propensity for locoregional tumor infiltration. The rich lymphatic network of the oropharynx predisposes tumors in this area to manifest early regional lymph node involvement. The achievement of locoregional control is central to the successful outcome in oropharynx cancer and relates directly to overall survival [5].

The optimal treatment for these cancers is disputed, but it is generally accepted that for early stage disease, surgery or radiotherapy (RT) alone achieves similar survival rates.

Considerable controversy exists about the appropriate treatment modality for locoregionally advanced oropharyngeal squamous cell carcinomas (LAOSCC). Nowadays, chemoradiotherapy is generally considered as an effective option when thinking about a functional preservation and RT is usually recommended as an adjuvant treatment option after surgical resection of these tumors, in patients with advanced stage cancers [6]. However, the 
toxicity of concurrent chemoradiotherapy (CCRT) is a major concern, sometimes with the necessity of hospitalization and nutritional support [7]. On the other hand, surgical management of persistent or recurrent LAOSCC after failure of chemoradiotherapy is associated with high complication rates [8].

Currently, in our institution, the main approach in LAOSCC in patients with favorable medical conditions consists of concurrent chemoradiotherapy with a regimen of taxane, platinum and fluorouracil.

Recently, the focus has centered on CCRT protocols, $[7,9]$ but only a few anatomic site-specific randomized trials evaluating the outcomes after primary surgical treatment vs. nonsurgical treatment of LAOSCC are available.

The aim of the present study was to compare retrospectively the results obtained by different treatment strategies in our Institution for LAOSCC: primary surgical resection followed by concurrent chemoradiotherapy and concurrent chemoradiotherapy alone.

\section{Methods}

\subsection{Study Design}

A total of 57 patients stage III/IV (American Joint Committee of Cancer (AJCC), 7th edition, 2010) were treated with isolated or postoperative chemoradiotherapy for squamous cell carcinoma of the oropharynx at the Portuguese Institute of Oncology of Oporto between January 2005 and December 2009 and included in this analysis. The data of these patients were obtained from a database of 204 oropharynx cancer patients. Excluded from the study were those who presented a previous history of head and neck cancer, stage I and II disease, distant metastasis or irresectable disease, synchronous primary lesions, patients who had palliative treatment or part of the treatment in another institution, Karnofsky performance status $<60 \%$, those who had surgery or radiotherapy alone or surgery followed only by radiotherapy, incomplete information or no follow-up available.

Treatment options depended mainly on the patient's as well as on the physician's preference according to multidisciplinary group decision. Data from 17 patients treated with surgery plus chemoradiotherapy were compared with 40 patients treated with definitive chemoradiotherapy. The two groups were selected according to five similar characteristics: age, gender, tumor site (tonsil and soft palate vs. tongue base and vallecula), N-category (N0 vs. N+) and AJCC stage (III vs. IV, according to AJCC classification, 7th edition).

\subsection{Pretreatment and Post-Treatment Evaluation}

Prior to the first treatment and after any treatment modal- ity all patients were evaluated by our multidisciplinary group of physicians, including head and neck surgeons, radiation oncologists, medical oncologists and radiologists.

All patients were initially evaluated by complete physical examination, head and neck computed tomography (CT) and magnetic resonance imaging (MRI) in selected cases. In advanced $\mathrm{N}$ stages, patients were submitted to positron emission tomography in order to detect distant metastasis leading to different treatment options. The routine follow-up program in our institution consists of a clinical observation every 3 months. CT scan and/or MRI were performed between 8 - 12 weeks after treatment.

\subsection{Treatment}

\subsubsection{Surgery plus Chemoradiotherapy}

Surgery was performed to resect the primary tumor. Different types of neck dissections were associated according to the stage of the disease: in 4 cases no lymph node dissection was performed, ipsilateral and bilateral neck dissections were performed in 4 and 9 cases, respectively.

Three-dimensional conformal radiotherapy with a multileaf collimator was performed in all patients using 4 - $6 \mathrm{MV}$ photons from a linear accelerator with conventionally fractionation (2 Gy/fraction, once daily, five times weekly), 6 - 8 weeks after surgery. The treatment field included the entire primary tumor area, all extensions of the surgical scar and the upper and middle lymphatic drainage areas. Total dose at the primary site was 60 - $66 \mathrm{~Gy}$, according to the limits of the surgical margins. In the lymph node area, doses were between 50 and $66 \mathrm{~Gy}$, according to the type of nodal invasion observed surgically and on histopathological diagnosis following neck dissection.

All these patients had high risk factors such as positive surgical margins, extracapsular spread of lymph nodes metastasis and lympho-vascular or perineural invasion and consequently all received concurrent chemotherapy in addition to radiotherapy. Concurrent chemotherapy consisted of $100 \mathrm{mg} / \mathrm{m}^{2}$ of cisplatin on radiotherapy days 1, 22 and 43. All patients eligible for chemotheraphy received prophylatic hydration and antiemetic agents.

\subsubsection{Definitive Chemoradiotherapy}

Forty patients received conventionally fractionated radiotherapy (5 fractions per week) with doses per fraction of $2.0 \mathrm{~Gy}$. Radiotherapy was performed with a linear accelerator and 4 - 6 MV photons. The total dose delivered to the primary tumor and the involved lymph nodes was $70 \mathrm{~Gy}$. In clinically uninvolved cervical and supraclavicular lymph nodes total dose administered was 50 $60 \mathrm{~Gy}$. Concurrent chemotherapy consisted of $100 \mathrm{mg} /$ 
$\mathrm{m}^{2}$ of cisplatin on radiotherapy days 1,22 and 43.

\subsection{Study End-Points and Statistical Considerations}

All the variables were evaluated using the Pearson chisquare test, fisher's exact test, Mann-Whitney test and the student $\mathrm{t}$ test to determine any significant differences between the two groups.

Both treatment groups were compared for one-year and two-years loco-regional control (LC), disease-free survival (DFS) and overall survival (OS), referenced from the last day of radiotherapy.

LC, DFS and OS estimate rates were calculated using the Kaplan-Meier method. Differences between the Kaplan-Meier curves were calculated with the Wilcoxon test. Prognostic factors found to be significant $(\mathrm{p}<0.05)$ in the univariate analysis were included in a multivariate analysis, performed with the Cox proportional hazards model. The primary goal of this study was to compare the results of definitive chemoradiotherapy to surgery followed by chemoradiotherapy.

The levels of statistical significance were calculated at the $5 \%$ level of probability $(\mathrm{p}<0.05)$. Statistical analyses were conducted using the Statistical Package for Social Sciences, version 19.0 for Windows (SPSS, Chicago, IL).

\section{Results}

\subsection{Demographics}

A total of 17 patients with LAOSCC treated by primary surgical resection followed by CCRT were matched to 40 patients treated only with CCRT according to gender, age, tumor site, nodal status and overall stage. The characteristics of the two groups are listed in Tables $\mathbf{1}$ and 2. All patients were men with an age range of 38 - 74 years. The median age was 57 years for surgical patients and 53 years for CCRT patients ( $p=0.474)$. The two groups did not differ significantly with respect to $\mathrm{N}$-category ( $\mathrm{p}=$ $0.633)$ and T-category ( $p=0.015)$.

\subsection{Surgery plus Chemoradiotherapy Group}

In the surgical group, four patients underwent unilateral and nine bilateral neck dissection. The remaining four did not undergo neck dissection.

After surgery, patients were restaged according to the histopatological results (Table 3).

\subsection{Survival Analysis}

On univariate analysis, treatment regimen $(p=0.016$, Figure 1) and AJCC-stage ( $p=0.035)$ were associated with LC. The results of the univariate analysis for LC are summarised in Table 4. On multivariate analysis directed
Table 1. Patients characteristics of both treatment groups.

\begin{tabular}{|c|c|c|c|}
\hline Characteristic & $\begin{array}{c}\text { Surgery + CCRT } \\
(\mathrm{n}=17)\end{array}$ & $\begin{array}{l}\text { CCRT } \\
(\mathrm{n}=40)\end{array}$ & $\mathrm{p}$ \\
\hline \multicolumn{4}{|l|}{ Gender n (\%) } \\
\hline Male & $17(100.0)$ & $40(100.0)$ & 1.000 \\
\hline \multicolumn{4}{|l|}{ Age n (\%) } \\
\hline$<55$ years & $7(41.2)$ & $22(55.0)$ & \multirow{3}{*}{0.561} \\
\hline 55 - 59 years & $3(17.6)$ & $7(17.5)$ & \\
\hline$>59$ years & $7(41.2)$ & $11(27.5)$ & \\
\hline \multicolumn{4}{|l|}{ Subsite n (\%) } \\
\hline $\begin{array}{l}\text { Palatine tonsil and } \\
\text { soft palate }\end{array}$ & $11(64.7)$ & $21(52.5)$ & \multirow{2}{*}{0.396} \\
\hline $\begin{array}{l}\text { Base of the tongue } \\
\text { and vallecule }\end{array}$ & $6(35.3)$ & $19(47.5)$ & \\
\hline \multicolumn{4}{|l|}{ Nodal status n (\%) } \\
\hline Negative & $6(35.3)$ & 15 (37.5) & \multirow{2}{*}{0.874} \\
\hline Positive & $11(64.7)$ & 25 (62.5) & \\
\hline \multicolumn{4}{|l|}{ AJCC-stage n (\%) } \\
\hline III & $10(58.8)$ & $17(42.5)$ & \multirow{2}{*}{0.259} \\
\hline IV & $7(41.2)$ & $23(57.5)$ & \\
\hline \multicolumn{4}{|l|}{ T-category n (\%) } \\
\hline $\mathrm{T} 1$ & $1(5.9)$ & $0(0.0)$ & \multirow{4}{*}{0.015} \\
\hline $\mathrm{T} 2$ & $6(35.3)$ & $3(7.5)$ & \\
\hline T3 & $7(41.2)$ & $20(50.0)$ & \\
\hline $\mathrm{T} 4$ & $3(17.6)$ & $17(42.5)$ & \\
\hline \multicolumn{4}{|l|}{ N-category n (\%) } \\
\hline N0 & $6(35.3)$ & 15 (37.5) & \multirow{4}{*}{0.633} \\
\hline N1 & $5(29.4)$ & $14(35.0)$ & \\
\hline N2 & $6(35.3)$ & $9(22.5)$ & \\
\hline N3 & $0(0.0)$ & $2(5.0)$ & \\
\hline \multicolumn{4}{|l|}{$\begin{array}{l}\text { Follow-up of } \\
\text { survivors (months) }\end{array}$} \\
\hline Median (range) & $31(22-58)$ & $39.5(22-70)$ & 0.123 \\
\hline
\end{tabular}

Abbreviations: CCRT = concurrent chemoradiotherapy.

Table 2. Distribution of patients by $\mathrm{T}$ and $\mathrm{N}$.

\begin{tabular}{cccccc}
\hline \multirow{2}{*}{ Treatment } & \multicolumn{5}{c}{ N Stage } \\
\cline { 2 - 6 } Surgery + CCRT & N0 & N1 & N2 & N3 & Total \\
T1 & 0 & 0 & 1 & 0 & 1 \\
T2 & 0 & 4 & 2 & 0 & 6 \\
T3 & 6 & 0 & 1 & 0 & 7 \\
T4a & 0 & 1 & 2 & 0 & 3 \\
Total & 6 & 5 & 6 & 0 & 17 \\
CCRT & & & & & \\
T2 & 0 & 1 & 1 & 1 & 3 \\
T3 & 10 & 6 & 3 & 1 & 20 \\
T4a & 5 & 7 & 5 & 0 & 17 \\
Total & 15 & 14 & 9 & 2 & 40 \\
\hline
\end{tabular}

Abbreviations as in Table 1. 
Table 3. Distribution of surgical patients by pre and postoperative stage.

\begin{tabular}{ccccc}
\hline & \multicolumn{2}{c}{$\begin{array}{c}\text { Palatine tonsil and } \\
\text { soft palate }\end{array}$} & \multicolumn{2}{c}{$\begin{array}{c}\text { Base of the tongue } \\
\text { and vallecule }\end{array}$} \\
\hline AJCC stage & III & IV & III & IV \\
\hline Pre-operative & 8 & 2 & 3 & 4 \\
Postoperative & 1 & 10 & 1 & 5 \\
\hline
\end{tabular}

Table 4. Univariate analysis for loco-regional control.

\begin{tabular}{|c|c|c|c|c|}
\hline & At 1-year (\%) & $\mathrm{p}$ & At 2-years (\%) & $\mathrm{p}$ \\
\hline \multicolumn{5}{|l|}{ Treatment } \\
\hline Surgery + CCRT & 94.1 & \multirow{2}{*}{0.015} & 94.1 & \multirow{2}{*}{0.016} \\
\hline CCRT & 62.5 & & 55.0 & \\
\hline \multicolumn{5}{|l|}{ Age } \\
\hline$<55$ years & 65.5 & \multirow{3}{*}{0.544} & 62.1 & \multirow{3}{*}{0.764} \\
\hline 55 - 59 years & 80.0 & & 80.0 & \\
\hline$>59$ years & 77.8 & & 77.8 & \\
\hline \multicolumn{5}{|l|}{ Subsite } \\
\hline $\begin{array}{l}\text { Palatine tonsil and } \\
\text { soft palate }\end{array}$ & 75.0 & \multirow{2}{*}{0.559} & 68.8 & \multirow{2}{*}{0.514} \\
\hline $\begin{array}{l}\text { Base of the tongue } \\
\text { and vallecule }\end{array}$ & 68.0 & & 64.0 & \\
\hline \multicolumn{5}{|l|}{ T-category } \\
\hline T1-2 & 80.0 & \multirow{3}{*}{0.335} & 80.0 & \multirow{3}{*}{0.089} \\
\hline T3 & 77.8 & & 70.4 & \\
\hline $\mathrm{T} 4$ & 60.0 & & 55.0 & \\
\hline \multicolumn{5}{|l|}{ Nodal status } \\
\hline Negative & 85.7 & \multirow{2}{*}{0.077} & 81.0 & \multirow{2}{*}{0.196} \\
\hline Positive & 63.9 & & 58.3 & \\
\hline \multicolumn{5}{|l|}{ AJCC-stage } \\
\hline III & 85.2 & \multirow{2}{*}{0.035} & 81.5 & \multirow{2}{*}{0.069} \\
\hline IV & 60.0 & & 53.3 & \\
\hline Entire cohort & 71.9 & & 66.7 & \\
\hline
\end{tabular}

Abbreviations as in Table 1.

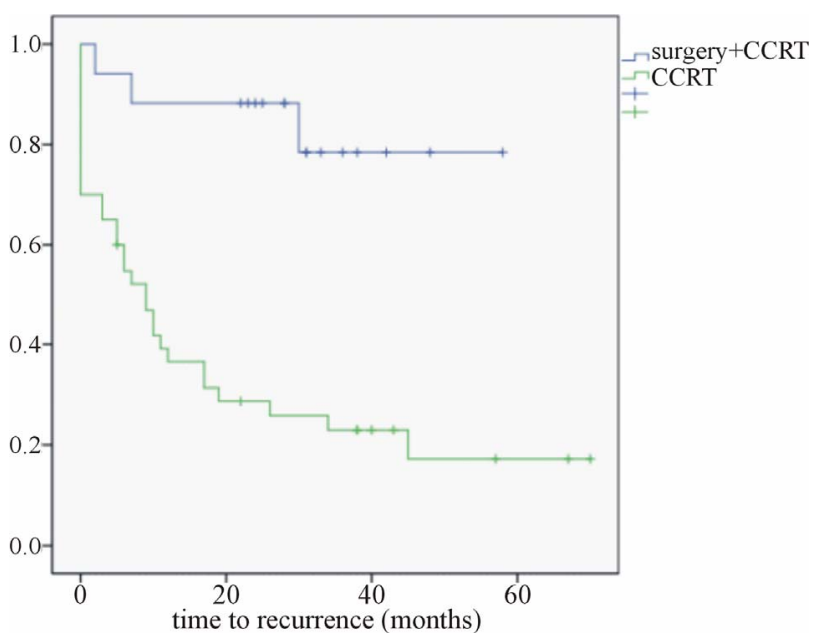

Figure 1. Comparison of both treatment groups (surgery plus chemoradiotherapy and chemoradiotherapy) with respect to loco-regional control. to LC, treatment regimen (risk ratio [RR] 9.43; 95\%confidence interval [CI] 1.25 - 71.28; $\mathrm{p}=0.030$ ), maintained significance. AJCC-grade (RR 2.67; 95\%-CI 0.95 - 7.50; $\mathrm{p}=0.063$ ) was almost significant.

On univariate analysis, treatment regimen $(\mathrm{p}<0.001$, Figure 2) and AJCC-stage ( $p=0.05)$ were associated with DFS. The results of the univariate analysis of DFS are summarized in Table 5. On multivariate analysis to DFS treatment regimen (RR 6.54; 95\%-CI 1.98 - 21.61;

Table 5. Univariate analysis for disease free survival.

\begin{tabular}{|c|c|c|c|c|}
\hline & At 1-year (\%) & $\mathrm{p}$ & At 2-years (\%) & $\mathrm{p}$ \\
\hline \multicolumn{5}{|l|}{ Treatment } \\
\hline Surgery + CCRT & 88.2 & \multirow{2}{*}{$<0.001$} & 88.2 & \multirow{3}{*}{$<0.001$} \\
\hline CCRT & 37.5 & & 27.5 & \\
\hline Age & & & & \\
\hline$<55$ years & 55.2 & \multirow{4}{*}{0.678} & 44.8 & \multirow{4}{*}{0.872} \\
\hline 55 - 59 years & 40.0 & & 40.0 & \\
\hline$>59$ years & 55.6 & & 50.0 & \\
\hline \multicolumn{3}{|l|}{ Subsite } & & \\
\hline $\begin{array}{l}\text { Palatine tonsil and } \\
\text { soft palate }\end{array}$ & 53.1 & \multirow[b]{2}{*}{0.933} & 50.0 & \multirow[b]{2}{*}{0.452} \\
\hline $\begin{array}{l}\text { Base of the tongue } \\
\text { and vallecule }\end{array}$ & 52.0 & & 40.0 & \\
\hline \multicolumn{5}{|l|}{ T-category } \\
\hline T1-2 & 70.0 & \multirow{3}{*}{0.275} & 70.0 & \multirow{3}{*}{0.109} \\
\hline T3 & 55.6 & & 48.1 & \\
\hline $\mathrm{T} 4$ & 40.0 & & 30.0 & \\
\hline \multicolumn{5}{|l|}{ Nodal status } \\
\hline Negative & 57.1 & \multirow{2}{*}{0.602} & 57.1 & \multirow{2}{*}{0.182} \\
\hline Positive & 50.0 & & 38.9 & \\
\hline \multicolumn{5}{|l|}{ AJCC-stage } \\
\hline III & 63.0 & \multirow{2}{*}{0.138} & 59.3 & \multirow{2}{*}{0.050} \\
\hline IV & 43.3 & & 33.3 & \\
\hline Entire cohort & 52.6 & & 45.6 & \\
\hline
\end{tabular}

Abbreviations as in Table $\mathbf{1 .}$

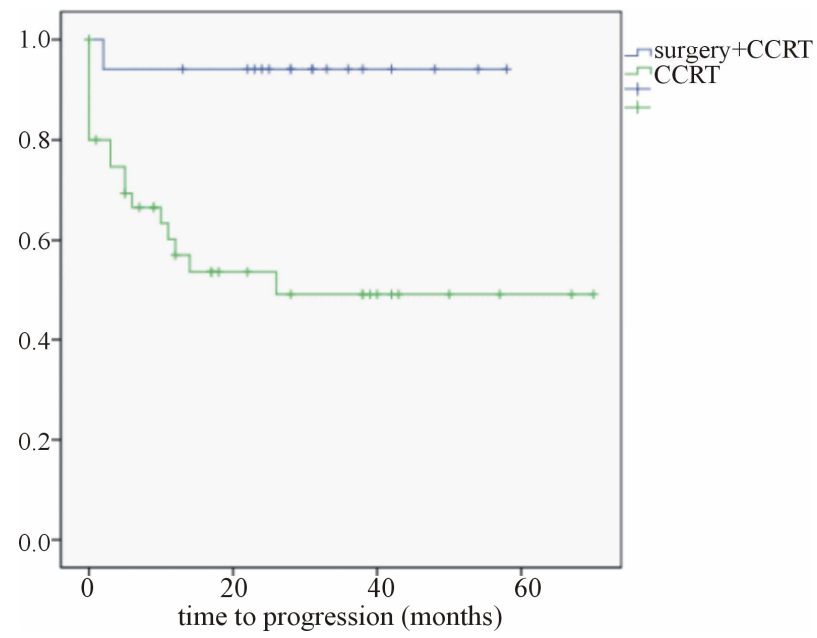

Figure 2. Comparison of both treatment groups (surgery plus chemoradiotherapy and chemoradiotherapy) with respect to progression free survival. 
$\mathrm{p}=0.002)$ option was significant as AJCC-stage (RR 2.00; 95\%-CI 0.97 - 4.13; $\mathrm{p}=0.062$ ).

In the surgical group, one patient developed locoregional recurrence and another lung metastatis (Table 6).

In the CCRT group a total of 4 patients suffered disease progression. After treatment, 6 patients presented persistence of the disease. Three of these patients underwent neck dissection and one patient underwent salvage surgery. Recurrence or another tumor developed in a total of 17 patients (Table 6).

Follow-up time of the survival group was $22-70$ months (with a median of 31 months for the surgery plus CCRT group and 39.5 months for the CCRT group). Although the median follow-up of survivors was longer in the CCRT group, the difference did not reach statistical significance (Table 2).

On univariate analysis, treatment regimen $(p=0.002$, Figure 3), age $(p=0.012)$ and T-category $(p=0.012)$ were associated with better OS. The results of the univariate analysis of OS are summarized in Table 7. On multivariate analysis, treatment regimen (RR 3.86; 95\%-CI 1.09 - 13.61; $\mathrm{p}=0.036$ ) maintained significance. T-category (RR 1.508; 95\%-CI $0.88-2.58$; p = 0.134) and age (RR 1.26; 95\%-CI 0.84 - 1.89; $\mathrm{p}=0.253$ ) were not significant.

Three patients of the group treated with surgery plus CCRT died. In the group treated with CCRT, 26 patients died. Of these 29 patients, 18 died of disease, 2 of second primary tumors and 9 from unrelated causes.

Two patients from the surgery plus CCRT group suffered tumor recurrence compared with 27 from the CCRT group, who experienced recurrence or progression. The 3-year DFS estimate rate was $78.4 \%$ for the surgical group and $23.0 \%$ for the CCRT group. Figure 2 shows the Kaplan-Meier PFS curve for the surgery plus CCRT group versus the CCRT group. Significant difference was found in the mean PFS between the 2 groups ( $<<0.001)$.

Table 6. Distribution of patients by type of recurrence.

\begin{tabular}{|c|c|c|c|c|}
\hline \multirow[t]{2}{*}{ Recurrence } & \multicolumn{2}{|c|}{$\begin{array}{c}\text { Surgery + CCRT } \\
n=17\end{array}$} & \multicolumn{2}{|c|}{$\begin{array}{l}\text { CCRT } \\
\mathrm{n}=40\end{array}$} \\
\hline & n (\%) & Deaths (n) & n (\%) & Deaths (n) \\
\hline No relapse & $14(82.3)$ & 0 & 13 (32.5) & 4 \\
\hline Primary site & $0(0.0)$ & 0 & $6(15.0)$ & 6 \\
\hline Neck & $0(0.0)$ & 0 & $1(2.5)$ & 1 \\
\hline $\begin{array}{c}\text { Simultaneous } \\
\text { primary site and neck }\end{array}$ & $1(5.9)$ & 1 & $3(7.5)$ & 3 \\
\hline $\begin{array}{c}\text { Distant } \\
\text { metastases }\end{array}$ & $1(5.9)$ & 1 & $4(10.0)$ & 4 \\
\hline $\begin{array}{c}\text { Secondary ENT } \\
\text { localization }\end{array}$ & $0(0.0)$ & 0 & $1(2.5)$ & 0 \\
\hline $\begin{array}{c}\text { Secondary no ENT } \\
\text { localization }\end{array}$ & $1(5.9)$ & 1 & $2(5.0)$ & 1 \\
\hline
\end{tabular}

Abbreviations as in Table 1.
Table 7. Univariate analysis of overall survival.

\begin{tabular}{|c|c|c|c|c|}
\hline & At 1-year (\%) & $\mathrm{p}$ & At 2-years (\%) & $\mathrm{p}$ \\
\hline \multicolumn{5}{|l|}{ Treatment } \\
\hline Surgery + CCRT & 94.1 & \multirow{2}{*}{0.047} & 88.2 & \multirow{2}{*}{0.002} \\
\hline CCRT & 70.0 & & 45.0 & \\
\hline \multicolumn{5}{|l|}{ Age } \\
\hline$<55$ years & 86.2 & \multirow{3}{*}{0.195} & 62.1 & \multirow{3}{*}{0.012} \\
\hline 55 - 59 years & 60.0 & & 40.0 & \\
\hline$>59$ years & 72.2 & & 61.1 & \\
\hline \multicolumn{5}{|l|}{ Subsite } \\
\hline $\begin{array}{l}\text { Palatine tonsil and } \\
\text { soft palate }\end{array}$ & 68.8 & \multirow{2}{*}{0.086} & 59.4 & \multirow{2}{*}{0.798} \\
\hline $\begin{array}{l}\text { Base of the tongue } \\
\text { and vallecule }\end{array}$ & 88.0 & & 56.0 & \\
\hline \multicolumn{5}{|l|}{ T-category } \\
\hline T1-2 & 100.0 & \multirow{3}{*}{0.098} & 90.0 & \multirow{3}{*}{0.012} \\
\hline T3 & 77.8 & & 63.0 & \\
\hline $\mathrm{T} 4$ & 65.0 & & 35.0 & \\
\hline \multicolumn{5}{|l|}{ Nodal status } \\
\hline Negative & 81.0 & \multirow{2}{*}{0.605} & 66.7 & \multirow{2}{*}{0.306} \\
\hline Positive & 75.0 & & 52.8 & \\
\hline \multicolumn{5}{|l|}{ AJCC-stage } \\
\hline III & 81.5 & \multirow{2}{*}{0.464} & 70.4 & \multirow{2}{*}{0.070} \\
\hline IV & 73.3 & & 46.7 & \\
\hline Entire cohort & 77.2 & & 57.9 & \\
\hline
\end{tabular}

Abbreviations as in Table 1.

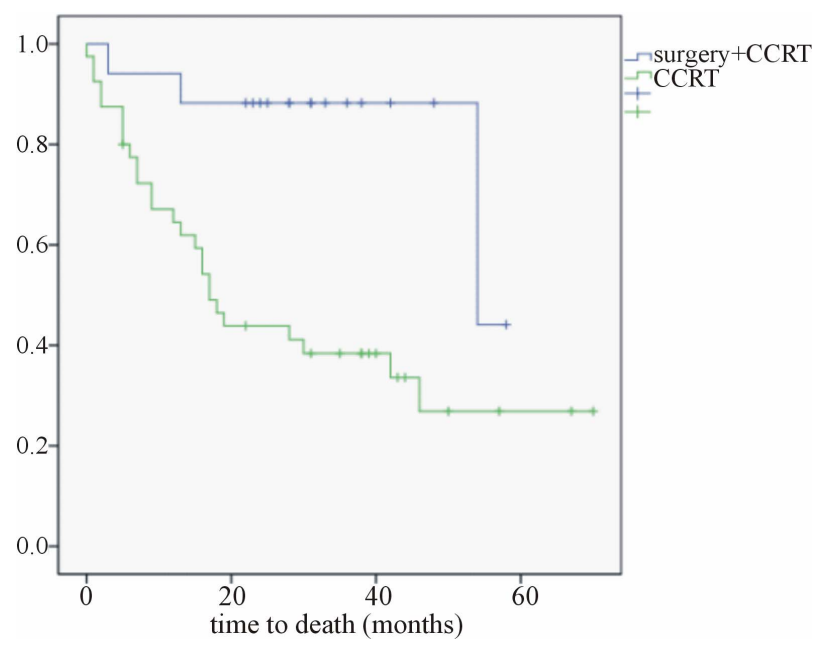

Figure 3. Comparison of both treatment groups (surgery plus chemoradiotherapy and chemoradiotherapy) with respect to overall survival.

The 3-year OS estimate rate was $88.2 \%$ for those who had undergone surgery plus CCRT and 26.9\% for the patients who received CCRT. Figure 3 shows the Kaplan-Meier OS curve for the surgery plus CCRT group versus the CCRT group. The difference in mean OS be- 
tween the 2 groups was statistically significant $(\mathrm{p}=$ 0.003).

\section{Discussion}

Squamous cell carcinoma of the oropharynx represents a great therapeutic challenge. Historical approaches to the management of this disease included initially radical surgery. Surgical approaches for these tumors can profoundly affect crucial daily activities, such as respiration, speech, chewing, swallowing and facial cosmesis with the respective emotional and social hardships.

Since the 1960s, RT alone has been considered the standard for oropharyngeal cancer treatment in many institutions, regardless of tumor stage [10,11].

In the past decade, several trials were consistent in showing a significant increase in locoregional control and organ preservation rates in patients randomized to receive CCRT compared with those who received RT alone $[12,13]$.

Until today, chemoradiotherapy-based regimens have been increasingly integrated into first-line therapy for advanced oropharyngeal carcinomas. However, no randomized trials have been conducted comparing oncologic results of surgery vs. CCRT in patients with LAOSCC. One nonanatomic site-specific randomized comparison of surgery plus postoperative radiotherapy (PORT) vs. CCRT was done, including only 21 patients with oropharyngeal carcinoma. Although this study showed no significant differences in the 3-year disease-free survival rate between surgery and CCRT, a subset analysis of patients with oropharyngeal cancer was not performed [14].

In a region with an incidence of 85 new cases of oropha ryngeal tumors, our institution treats nearly 40 cases per year. We decided to conduct a retrospective study to evaluate survival outcomes in patients with LAOSCC treated with surgery and CCRT vs. CCRT alone. The two groups of patients were selected according to similar potential confounding variables known to influence the prognosis.

In the present analysis, treatment with CCRT alone was associated with an increased risk of death and progression, compared with surgery plus CCRT. Data from patients undergoing surgery and CCRT were impressive, with a 3-year OS and DFS rate of $88 \%$ and $78 \%$, respectively. The 2-year actuarial LRC rate was $94 \%$. On the other hand, the CCRT group showed a 3-year OS and DFS rate of $27 \%$ and $23 \%$, respectively and a 2 -year actuarial LRC rate of 55\%. These differences were statistically significant.

A recent matched-pair study was conducted in Italy toevaluate survival outcomes in patients with LAOSCC treated with surgery and PORT vs. induction chemotherapy/CCRT. The clinical efficacy of chemoradiother- apy was as good as surgical resection and PORT, with a 3 -year OS and DFS rate of $71 \%$ and $73 \%$, respectively. The 3-year actuarial rate of local control was $79 \%$ and regional control was $80 \%$ [15].

In a trial of CCRT for LAOSCC, Calais et al. [12] also reported a higher 3-year overall survival rate (51\%).

This might have resulted because in our study more patients with advanced stage (Stage T4 and N3) were included in the CCRT group. Also, the differences in treatment protocols might have some influence, since our protocol did not consist of a sequential chemoradiotherapy and did not include 5-fluorouracil, with potential systemic effect on distant micrometastases [16].

Furthermore, we did not evaluate comorbidities which can also be a prognostic factor. Although it is difficult to determine whether the cause of death was related or not to the type of cancer therapy, treatment-related mortality should not be underestimated in patients undergoing aggressive multimodality regimens. Argiris et al. [17] reported a death rate of $15 \%$ related to treatment complications after CCRT.

The advent of new targeted therapies and the emerging role of HPV in oropharyngeal carcinoma might influence the choice of therapeutic approach. Patients with HPVpositive oropharyngeal tumors tend to have a better prognosis than those with tobacco- and/or alcohol-related tumors. This has been attributed to enhanced radiation sensitivity [18]. In our geographic region, tobacco- and alcohol-related oropharyngeal cancers remain dominant and the standard use of aggressive multimodality regimens for the treatment of LAOSCC may represent overtreatment in regions with a high incidence of HPV-related oropharyngeal carcinoma [19].

The primary limitations of the present study are the relatively small sample size and the different size of the two groups, which limited the statistical power, its nonrandomized nature and retrospective comparison. Although the matching procedure can limit the bias resulting from potential confounders, this was not a matchedpair analysis, so it had some intrinsic limits. Patients were similar with respect to age, gender, nodal status, subsite and overall stage. However, an imbalance was still present in these variables. Other variables that might have prognostic significance, including $\mathrm{T}$ and $\mathrm{N}$ category, had a different distribution in the two groups. In the case of $\mathrm{T}$ category it was statistically significant, with the proportion of Stage T4 disease in the CCRT greater than that of the surgical group.

With respect to distant failure, the 2-year rate of patients who developed distant metastases was greater in the CCRT group ( $10 \%$ vs. $6 \%$ ).

Although currently the most widely accepted treatment for LAOSCC is a sequential chemoradiotherapy, this study showed that surgery has an important role as a 
primary therapeutic modality in the treatment of selected cases of LAOSCC and is related with a significant better overall survival, progression-free survival and locoregional control rates.

\section{Conclusion}

According to this study, including surgery as an initial therapeutic option in the treatment of selected cases of LAOSCC, followed by CCRT may lead to better overall survival, progression-free survival and locoregional control rates and an apparent lower risk of death or tumor progression. For this reason, surgery has an important role as a primary therapeutic choice in the treatment of LAOSCC.

\section{REFERENCES}

[1] P. J. Bradley, "Management of Squamous Cell Carcinoma of the Oropharynx," Current Opinion in Otolaryngology and Head and Neck Surgery, Vol. 8, No. 2, 2000, pp. 80-86. http://dx.doi.org/10.1097/00020840-200004000-00002

[2] M. L. Gillison, "Current Topics in the Epidemiology of Oral Cavity and Oropharyngeal Cancers," Head and Neck, Vol. 29, No. 8, 2007, pp. 779-792. http://dx.doi.org/10.1002/hed.20573

[3] Registo Oncológico Regional do Norte (RORENO). http://www.ipoporto.pt/sobre/universo-ipo-porto/

[4] A. K. Chaturvedi, E. A. Engels, W. F. Anderson and M. L. Gillison, "Incidence Trends for Human PapillomavirusRelated and Unrelated Oral Squamous Cell Carcinomas in the United States," Journal of Clinical Oncology, Vol. 26, No. 4, 2008, pp. 612-619. http://dx.doi.org/10.1200/JCO.2007.14.1713

[5] J. C. Wadsley and S. M. Bentzen, "Investigation of Relationship between Change in Locoregional Control and Change in Overall Survival in Randomized Controlled Trials of Modified Radiotherapy in Head-and-Neck Cancer," International Journal of Radiation Oncology*Biology *Physics, Vol. 60, No. 5, 2004, pp. 1405-1409.

[6] R. E. Lundahl, R. L. Foote, J. A. Bonner, V. J. Suman, J. E. Lewis, et al., "Combined Neck Dissection and postoperative Radiation Therapy in the Management of the High-Risk Neck: A Matched-Pair Analysis,” International Journal of Radiation Oncology*Biology*Physics, Vol. 40, No. 3, 1998, pp. 529-534.

[7] U. Duvvuri and J. N. Myers, "Contemporary Management of Oropharyngeal Cancer: Anatomy and Physiology of the Oropharynx," Current Problems in Surgery, Vol. 46, No. 2, 2009, pp. 119-184. http://dx.doi.org/10.1067/j.cpsurg.2008.10.003

[8] J. M. Bumpous, "Surgical Salvage of Cancer of the Oropharynx after Chemoradiation," Current Oncology Reports, Vol. 11, No. 2, 2009, pp. 151-155. http://dx.doi.org/10.1007/s11912-009-0022-6

[9] J. T. Parsons, W. M. Mendenhall, S. P. Stringer, R. J. Amdur, R. W. Hinerman, et al., "Squamous Cell Carci- noma of the Oropharynx Surgery, Radiation Therapy, or Both,” Cancer, Vol. 26, No. 11, 2002, pp. 612-619.

[10] D. A. Fein, W. R. Lee, W. R. Amos, R. W. Hinerman, J. T. Parsons, et al., "Oropharyngeal Carcinoma Treated with Radiotherapy: A 30-Year Experience,” International Journal of Radiation Oncology*Biology*Physics, Vol. 34, No. 2, 1996, pp. 289-296.

[11] J. P. Bataini, B. Asselain, C. Jaulerry, F. Burnin, J. Bernier, et al., “A Multivariate Primary Tumour Control Analysis in 465 Patients Treated by Radical Radiotherapy for Cancer of the Tonsillar Region: Clinical and Treatment Parameters as Prognostic Factors,” Radiotherapy \& Oncology, Vol. 14, No. 4, 1989, pp. 265-277.

http://dx.doi.org/10.1016/0167-8140(89)90138-2

[12] G. Calais, M. Alfonsi, E. Bardet, C. Sire, T. Germain, et al., "Randomized Trial of Radiation Therapy versus Concomitante Chemotherapy and Radiation Therapy for Advanced-Stage Oropharyngeal Carcinoma," Journal of the National Cancer Institute, Vol. 91, No. 24, 1999, pp. 2081-2086. http://dx.doi.org/10.1093/jnci/91.24.2081

[13] D. J. Adelstein, P. Lavertu, J. P. Saxton, M. Secic, B. J. Wood, et al., "Mature Results of a Phase III Randomized trial Comparing Concurrent Chemoradiotherapy with Radiation Therapy Alone in Patients with Stage III and IV Squamous Cell Carcinoma of the Head and Neck," Cancer, Vol. 88, No. 4, 2000, pp. 876-883. http://dx.doi.org/10.1002/(SICI)1097-0142(20000215)88: 4<876::AID-CNCR19>3.0.CO;2-Y

[14] K. C. Soo, E. H. Tan, J. Wee, B. Lim, D. C. Tai, et al., "Surgery and Adjuvant Radiotherapy vs. Concurrent Chemoradiotherapy in Stage III/IV Nonmetastatic Squamous Cell Head and Neck Cancer: A Randomized Comparison,” British Journal of Cancer, Vol. 93, No. 3, 2005, pp. 279-286. http://dx.doi.org/10.1038/sj.bjc.6602696

[15] P. Boscolo-Rizzo, A. Gava, V. Baggio, C. Marchiori, M. Stellin, et al., "Matched Survival Analysis in Patients with Locoregionally Advanced Resectable Oropharyngeal Carcinoma: Platinum-Based Induction and Concurrent Chemoradiotherapy versus Primary Surgical Resection," International Journal of Radiation Oncology*Biology* Physics, Vol. 80, No. 1, 2011, pp. 154-160.

[16] J. L. Lefebvre, D. Chevalier, B. Luboinski, A. Kirkpatrick, L. Collette and T. Sahmoud, and for the EORTC Head and Neck Cancer Cooperative Group, "Larynx Preservation in Pyriform Sinus Cancer: Preliminary Results of a European Organization for Research and Treatment of Cancer Phase III Trial," Journal of the National Cancer Institute, Vol. 88, No. 13, 1996, pp. 890-899.

http://dx.doi.org/10.1093/jnci/88.13.890

[17] A. Argiris, B. E. Brockstein, D. J. Haraf , K. M. Stenson, B. B. Mittal, et al., "Competing Causes of Death and Second Primary Tumors in Patients with Locoregionally Advanced Head and Neck Cancer Treated with Chemoradiotherapy," Clinical Cancer Research, Vol. 10, No. 6, 2004, pp. 1956-1962. http://dx.doi.org/10.1158/1078-0432.CCR-03-1077

[18] C. Fakhry, W. H. Westra, S. Li, A. Cmelak, J. A. Ridge, et al., "Improved Survival of Patients with Human Papillomavirus-Positive Head and Neck Squamous Cell Carcinoma in a Prospective Clinical Trial," Journal of the 
National Cancer Institute, Vol. 100, No. 4, 2008, pp. 261269. http://dx.doi.org/10.1093/jnci/djn011

[19] A. A. Forastiere, "Chemotherapy in the Treatment of
Locally Advanced Head and Neck Cancer,” Journal of Surgical Oncology, Vol. 97, No. 8, 2008, pp. 701-707. http://dx.doi.org/10.1002/jso.21012 